\title{
Research needs in foreign language teacher education: Insights from researchers in Poland, Portugal, and Turkey
}

\author{
Burçak Yılmaz Yakışık ${ }^{1}$ \\ Asuman Aş1k ${ }^{2}$ \\ ${ }^{1}$ Gazi University, Turkey / Contact: yyburcak@gmail.com \\ ${ }^{2}$ Gazi University, Turkey / Contact: asuman.asik@gmail.com
}

\begin{abstract}
Language teacher education (LTE) is a dynamic field which needs to keep abreast of the changes in other fields and the teacher-oriented developments. In the 21 st century, teacher education is required to meet the expectations of the pre-/in-service teachers, the learners, the technology, and the changing qualifications. In this sense, it is fundamental to investigate how the research trends in LTE should be shaped with a bottomup perspective. To this end, the current study aims to investigate the needs of academics and researchers in the field of LTE in a variety of contexts (i.e., Turkey, Portugal, and Poland). The study was conducted as a part of an Erasmus+ Project called ILTERG (International Language Teacher Education Research Group) co-funded by the Turkish National Agency and Erasmus+ Program. A total number of 139 participants from three countries participated in the study. The data were collected through a needs analysis survey and semi-structured interviews. Quantitative and qualitative analysis of the data revealed that all items in the survey might be guiding for the academics to conduct research on. The list of the research topics could guide novice and/or expert researchers to conduct further studies in LTE. (C) 2020 The Literacy Trek \& the Authors - Published by The Literacy Trek APA Citation
\end{abstract} Keywords language teacher education; needs analysis; research trends

Submission date

01.05.2020

Acceptance date

02.12 .2020

Yakışık, B. Y.., \& Aşık, A. (2020). Research needs in foreign language teacher education: Insights from researchers in Poland, Portugal, and Turkey. The Literacy Trek, 6(2), 1-27. https://doi.org/10.47216/literacytrek.730300

\section{Introduction}

The basic and the most straightforward interpretations of language teacher education (LTE) programs cover only some key points about the components of LTE. An example of this understanding can easily be seen in Freeman and Johnson's (1998) definition of LTE; as they stated, "learning to teach is a long-term complex 
developmental process that operates through participation in the school practices and contexts associated with learning and teaching." (p. 402). The researchers briefly focus on three main points in LTE. First, the teacher is the learner of teaching; second, schools are social contexts of teacher learning, and third, the pedagogical process of language teaching and learning is essential.

This perception, which could be considered as the cornerstone in language teaching education, has been reinterpreted in the new century. In this regard, many researchers have made a cogent contribution to the shaping of LTE. At the beginning of the $21^{\text {st }}$ century, Crandall (2000) yielded that language education programs combined the fields of applied linguistics, pedagogical education, and literature. Through these disciplines, theoretical knowledge and practical implications have been provided for both student teachers (STs) and experienced teachers. Though these components have remained as the fundamentals of LTE, they have been blended with new information and new perceptions brought by today's era.

There are two main streams of LTE programs. First, traditional teacher education programs regard the teacher as the passive receiver of the transmitted information, and therefore, teachers lack decision-making skills. The second view, on the other hand, has a constructivist perspective that enables the teacher to become the primary source of the knowledge throughout their career. Within this constructivist perspective, many researchers have been discussing a number of innovative topics in LTE such as 'teacher autonomy' (Benson, 2007; Huang, 2005; Ling, 2007), 'teacher efficacy' (Tschannen-Moran \& Hoy, 2001; Wyatt, 2014); and a more recent topic, teacher agency' (Pyhältö, Pietarinen, \& Soini, 2015), which is, briefly, being an active teacher and the capability of making decisions regarding their job. On one hand, these tendencies indicate how the research and the LTE have been developed in terms of theory and practical implications; on the other hand, the unresolved issue about the inefficiency of LTE programs has been kept in mind by several researchers and teacher educators. For example, in the late $20^{\text {th }}$ century and at the beginning of the $21^{\text {st }}$ century, the inefficiency of LTE programs was commonly discussed as these programs did not prepare the teachers for the realities of the classroom (Crandall, 2000). Wright (2010), in his detailed review of LTE, highlights the issue of theory and practice divide noting that theoretical foundations of teacher education programs 
are not applied to the daily realities. Johnson (2013) notes this major challenge in LTE programs and gives the big responsibility to the LTE programs so that these programs connect the theoretical concepts to everyday concepts of teaching along with concrete practical activities. The examples that display the gap between theory and practice in LTE can be expanded; however, investigating this gap is not the major concern of this study. Instead, examining the research needs within LTE is considered to act as a pioneer in the field of foreign language teacher education by inspiring new research areas and presenting views from teacher educators about the highly and moderately preferred research topics.

Revealing the research needs is believed to contribute to more studies in LTE which combine theory and practice. The importance and originality of this study are that the needs analysis survey has been conducted among language teacher educators and practitioners doing their post-graduate studies in language teacher education in three countries; Poland, Portuguese and Turkey. Furthermore, the views of three teacher educators from each country have been taken in order to gain insights about the highly and moderately preferred research topics and to understand current portrait in LTE. In particular, no study, to our knowledge, has considered revealing the research needs in the field of foreign language teacher education by examining three different countries, which also makes this study significant.

\section{Literature Review}

When the literature is examined thoroughly, it is observed that the first research topics about foreign LTE were drawn from "general education"; and therefore, the educational activities emerged as classroom observation, teaching young learners, action research, observation and supervision, language awareness, mentoring in the late $20^{\text {th }}$ century (Wright, 2010). As mentioned before, these research topics have found their way to new and more influential trends in the $21^{\text {st }}$ century.

The reflective practice flourished as one of the widely investigated research topics. Reflection, initially introduced by Schön $(1983 ; 1987)$, then elaborated by 
Barlett (1990) and Wallace (1991), leads to ST's' development of independent judgement and practical theory; thus, it has a substantial contribution to foreign language teaching education. The significant role of reflective practice is also highlighted by Richards (2004) reporting that the shift from behaviorism to constructivism enabled teachers to become reflective practitioners who could form their own working theory. In this regard, Farrell (2018) yields that reflection and reflective practice has been at the core of major innovations in LTE. Through reflective practice, STs act as active mediators of their own learning so that they take the responsibility of their development in their teaching career. Furthermore, by combining reflective practice with other research areas, El-Dib (2007) integrates reflective thinking and action research during a period of teaching practice on an Egyptian foreign language teaching undergraduate program. To examine the levels of reflective thinking, El-Dib (2007) constructs a three-part procedure of action research and reflective-planning, acting, and reviewing. The data displays that 50 percent of STs were only capable of 'low-level reflection'. The conclusion drawn by the researcher is that lack of awareness of the complexity of problems encountered in the classroom and lack of vision of their work as prospective teachers result in low-level reflection. Thus, in LTE programs, there is too much focus on 'foundations of education' and teaching methods, strategies, and techniques, which allocates little time for reflective thinking (El-Dib, 2007).

The existing research about the use of the reflective practice in LTE has been mostly carried out with STs. Some studies demonstrate that STs benefit from reflective practice as they explore their weaknesses and strengths (Lee, 2007; Luk, 2008; Yeşilbursa, 2011) whereas Akbari (2007) yields that reflective practice is not appropriate for this group as STs are at the early stages of their career, and they are more concerned about self-image and approval by their mentors.

Continuous professional development (CPD), another key topic, plays a major role in LTE research. Language teachers engage in CPD activities in various ways. Richards and Farrell (2005) emphasize that CPD has long-term goals such as realizing the process of language development, understanding the changing teachers' roles, being able to make decisions during lessons, examining one's own theories and 
principles of language teaching, developing an understanding of different teaching styles, and understanding learners' perceptions about classroom activities.

Conducting research and developing inquiry skills might be efficient tools for CPD. For instance, Matei (2002) examines the experience of introducing a group of Romanian undergraduate STs to classroom research as an experimental part of their teacher education program. STs report that researching with students in classrooms made them both reflective and realistic. Matei (2002) and her students finished the process by attending an international conference and giving joint presentations about their research. This stage was so significant as the STs not only engaged in the professional community of language teachers and researchers but also started their professional development journey being a member of the international community of language teachers. A similar study was conducted by Jones (2004) with a group of Australian undergraduate students in the LTE program. Participants report that they benefited from engaging in teacher research since the theoretical issues taught at the teacher education program became relevant as they worked with real learners in real classrooms. One can draw two conclusions from the studies where STs engage with teacher research. First, if CPD is a long process, STs take their initial steps into this long journey under the supervision of their teacher educators. Second, they get accustomed to making critical reflection about real classrooms, their research, and their projects. Based on the literature in reflective teaching and CPD, it is easily recognized that research about these two topics is interrelated and interconnected. Crandall (2000) supports this view by claiming that reflection and teacher inquiry are now regarded as important to the development of language teaching theory and appropriate LTE. Another study supporting this view was carried out with 217 English language teachers (Wichadee, 2012). This study illuminates that reflective practice plays a significant role in CPD as participants report that they have benefited from the reflective discussions with other colleagues. Therefore, these reflective discussions provide teachers with the opportunity for self-development. Another study which consolidates the positive link between reflection and CPD was conducted by Chien (2013). Participant teachers kept a journal as a reflective practice in Chien's study, and this constant journal keeping enabled teachers to work collaboratively with 
their colleagues, discuss journal entries, set clear goals, and make suggestions for professional development.

Cooperation and collaboration in professional development are frequently studied in the research of LTE. This collaboration might be both at macro and micro levels; it can be between teachers and mentors, only teachers, school administrators, educational institutions, governments (Bal-Gezegin \& Seferoglu, 2019). Novice teachers' and mentors' collaboration has been the focus of some studies. Mann and Tang (2012) reported that the interaction between the mentor teacher and the novice teacher was found to be useful for their professional growth. Meng and Tajaroensuk (2013) investigated the problems that EFL teachers at the tertiary level had during their in-service professional development. Participants highlighted the importance of teamwork and reported that the collaboration of teachers was valuable for growing professionally.

The significant role of technology in CPD has also been viewed for the last decade. Advances in technology have enabled teachers to use technological tools for professional development and even create a new research area called online professional development (Lin, 2015). Teachers are now supported by providing them with opportunities to attend online webinars, workshops, conferences, read academic publications, conduct research via the internet. The influence of virtual settings on teachers' professional development is investigated by other researchers. Kabilan, Adlina, and Embi (2011) found that online sharing and collaboration; engaging in online tasks enriched their profession in diverse ways. Rashid (2018) investigated the impact of dialogic reflections shared on a widely-used social-media platform on teachers' professional growth and concluded that internet sources contributed to the teacher's professional growth.

As mentioned above, reflective practice constitutes the core of major innovations in the area of LTE and the practitioners of reflective teaching did not keep distant to technology and investigated the implications of technology to promote reflective practice. Yang (2009) conducted a study with STs about the use of blogs. STs critically reflected on their learning process via posting messages on the blog or sending comments on their peers' posts. As a result, participants found this platform useful, enabling them to reflect on their experience and to cooperate with other peers. 
Video-recorded lessons are considered as valuable tools to foster reflection (Baecher et al., 2013; Eröz-Tuğa, 2013; Susoy, 2015).

Inquiring teacher beliefs has been another major research topic among LTE researchers. Crandall (2000) states that STs' prior knowledge; in other words, the influence of prior teacher educators and their beliefs have a profound impact on their conceptions of teaching and learning. Therefore, the teacher constructs his/her 'teaching beliefs', blending what s/he has experienced as a student and trainee and what s/he explores as a prospective teacher. In this regard, Gray (2004) contributes to this discussion, analyzing a different angle. An experienced teacher accumulates craft knowledge during his career; however, this knowledge cannot simply be learned in lectures, but it has to be 'explored'. The researcher attempts to outline how teachers' awareness is raised on a one-year postgraduate LTE program in the UK. The study involves a series of procedures such as reading published narrations which layout teacher knowledge, observation and discussion, planning, discussions of teaching dilemmas, and video recorded micro teachings and student research projects. She also supports this procedure by sharing her lesson planning and then teaching live classes, recording her immediate responses to incidents that happened in the classroom, and discussing these with STs. She also concludes that acquiring this craft knowledge is difficult, and all the mentioned procedures require the cooperation of a skillful teacher educator.

It is known that teachers are not merely responsible for fulfilling attained procedural tasks but are constantly thinking, making decisions, and solving problems. Constructivist teacher education, at this point, enables teachers to become aware of their own beliefs about the teaching process, make reflections on experience and collaborate with other teachers, take active roles in the decision-making process. That is why teacher beliefs and teacher cognition have expanded and brought about new intriguing research areas like teacher identity (De Costa \& Norton, 2017) and teacher agency (Husu \& Toom, 2008; Pyhältö, Pietarinen, \& Soini, 2015).

The concepts which have been the major research topics in LTE literature have been extensively studied in practicum context. Practicum teaching is the first authentic context where STs engage with the teaching procedure in the real work 
community. It is the place where they attempt to bridge the gap between theoretical teacher education and classroom realities for the first time (Eröz-Tuğa; 2013; Susoy, 2015). Furthermore, the essential roles of teachers as materials developer, decision maker, problem solver (Richards, 1990) has resulted in a need for teacher education programs that provide prospective teachers with the actual practice of the abovementioned skills. The study conducted by Richards and Crookes (1988) presents the longstanding tradition at practicum teaching. They examined many LTE programs and found that 75 percent of programs involved observing experienced teachers or peers, being observed by supervisors or mentor teachers, being responsible for classroom management, while also offering mentor teachers an opportunity to learn from their new colleagues (Stoynoff, 1999). A recent study that investigates the sense of professional teacher agency of TTs reports that the implementation of practicum teaching varies according to the country and educational context (Yakışık, Fişne, \& Ekşi, 2019) as STs confront various constraints and challenges as a consequence of resources and opportunities at their teaching contexts. The length of the practicum teaching, age of the participants, task contents play significant roles in STs' agentic behaviours.

The literature above partly portraits the studies done in the field of foreign LTE, all of which is guiding to investigate the research aims of the current study. There has been a growing interest in LTE research. Thus, the studies might broaden our knowledge of practice; however, as Wright (2010) states, 'we need to learn more about the effects of our practice in second LTE' (p. 289). In this way, the real contribution of LTE to the quality of language teaching can be observed, and the big issue of theory and practice divide in LTE can be resolved; thus, the innovative reflections of research can be facilitated in realities of classroom practice.

\section{Aim of the study}

With the changing demands and competencies in teacher qualifications and the rise of the 21st skills, the research trends in LTE need updates and revision. To the best of our knowledge, there is no previous study to shed light on the viewpoints of the academics to explore the research topics with a bottom-up approach in different countries. In this regard, the current study aims to investigate the needs of academics and researchers in the field of LTE in a variety of contexts (Turkey, Poland, and 
Portugal) and to explore the opinions of researchers in LTE in terms of current implementations on choosing research topics and sharing their suggestions for further studies. The study was conducted as a part of an Erasmus+ project called ILTERG (International Language Teacher Education Research Group) co-funded by the Turkish National Agency and Erasmus+ Program, which aims to promote the interaction among the international research groups in line with social and scientific advancements. The study is significant in the field of LTE as it aims to present a descriptive picture of the research needs of the LTE from different contexts in three countries, which can guide novice and/or expert researchers to conduct further studies in LTE. Moreover, the study is also significant as it explores the opinions of the researchers and TEs on choosing research topics to contribute to LTE field through the discussions held in context-specific aspects.

\section{Methodology}

\section{Research Context}

The study was one of the outputs of an Erasmus+ Project called ILTERG (International LTE Research Group) co-funded by the Turkish National Agency and Erasmus+ Program. The ILTERG Project, a Strategic Partnership project for higher education, aims at enhancing the visibility and impact of research conducted by the novice and expert researchers The Project was implemented between 2016 and 2019. Partner institutions were Gazi University (Turkey), Boğaziçi University (Turkey), University of Evora (Portugal) and Pomeranian University (Poland). The teacher trainers and researchers of LTE programmes participated in the Project. Through The ILTERG Project, several outputs focusing on LTE, such as collaborative international research articles, an international book, an international conference, and a guidebook for international research groups were produced. Moreover, each LTE contexts are explained in detail for a better understanding of the research context.

In Turkey, in order to become an English language teacher, one has to complete a Bachelor's degree (1st cycle) in an ELT programme. However, it is also possible for graduates from programmes such as English Literature, American Literature, and Linguistics to become teachers through a master's program in ELT 
without a thesis. Additionally, graduates or undergraduates of these programmes can attain the certificate of English language teaching after getting pedagogical training, which is also called pedagogical formation course, offered by Faculties of Education at some qualified universities. The research setting for data collection of this study was the universities in Turkey which offer the 1st (Bachelor of Art), 2nd (Master of Art), and 3rd cycle degrees (Doctorate) of LTE programmes.

In Poland, the graduates of a Bachelor's degree (1st cycle) from an LTE program can become an English language teacher in a primary school. Also, to be a qualified teacher in all types of schools (primary, secondary, or higher), it is necessary to have a Master's degree (2nd cycle). The data collected from Poland include the universities which have degrees at the Bachelor's and Master's levels in LTE.

Furthermore, to become an English language teacher in Portugal, one needs to complete a master's degree ( 2 nd cycle) in the field. The institutions for data collection of the study provide 1st (Bachelor of Art), 2nd (Master of Art), and 3rd cycle degrees (Doctorate). In Portugal, there are two different Master's programmes: (i) for Primary education (Year 3 and 4) and (ii) for Basic (Year 7-9) and Secondary (10-12) education.

The similarity of LTE programmes in Poland, Portugal and Turkey is that they all provide linguistic and teacher education specialized classes. Besides, STs are engaged in practicum experience in their teacher education studies. In practicum teaching, both 'school experience' and 'teaching experience' courses are implemented within teacher education programmes in three countries.

\section{Participants}

Since the study is conducted as part of a project, purposeful sampling was used. Purposeful sampling is a technique widely used in qualitative research for the identification and selection of information-rich cases for the most effective use of limited resources (Patton, 2015). With this sampling, the researcher can select participants and research contexts that are representative and associated with the phenomenon and research problem being studied (Creswell, 2007).

A total number of 139 participants $(74.1 \%$ female and $25.9 \%$ male) took part in the study. The age range of the participants is a large one from the twenties to the 
sixties. In particular, the majority of them (88\%) are aged between 25 and 59 years. The study was conducted in three countries, which are Turkey, Poland, and Portugal. Thus, regarding the nationalities and contexts, $51 \%$ of the participants were Turkish, $23 \%$ were Polish, $17 \%$ were 24 Portuguese, and 9\% of the researchers were from other nationalities such as Italian and American. As for the educational background, 118 researchers, who took this survey, have an MA or Ph.D. degree. The researchers have different academic positions (research assistants, lecturers, assistant professors, associate professors, and professors) at their university. The researchers vary in national/international publications. Nearly half of them (48.2\%) have a maximum five publications, whereas 35 participants $(\% 27.2 \%)$ have sixteen or more publications.

With regard to courses taught at the BA level, the researchers mostly lecture language skills-based courses, teacher training, and methodology courses. At the MA and $\mathrm{Ph} . \mathrm{D}$. levels, the researchers mostly lecture language teaching methodology, teacher training, and language skills-based course in a similar way. When the participants were asked about how they define themselves such as researcher, language teacher and teacher trainer (they can choose more than one), mostly they preferred to choose researcher $(69.1 \%)$, and language teacher $(60.4 \%)$ and then language teacher trainer $(51.8 \%)$

\section{Data Collection Instruments}

In order to explore the research needs of the academics and researchers in LTE, both quantitative and qualitative data collection instruments were used. For quantitative data collection, a needs analysis survey was applied to teacher trainers and researchers in LTE. For more depth discussion, semi-guided interviews were conducted to collect qualitative data.

\section{Needs Analysis Survey}

In an educational framework, needs analysis is defined as a process that determines the needs of a learner or a group of learners and arranging the needs based on their priorities (Richards \& Platt, 1992). As also suggested by Nunan (1998), needs analysis is a starting point of the design of a syllabus or a curriculum which caters to the needs of different stakeholders (e.g., teachers, learners, administrators). Similarly, 
Johns and Dudley-Evans (1991) present needs analysis as the neutral discovery of elements of the target situation. With these affordances of the use of needs analysis, the current study chose a needs analysis survey as an instrument to collect the data with a bottom-up approach. The development of the needs analysis survey for the current study is illustrated in Figure 1.

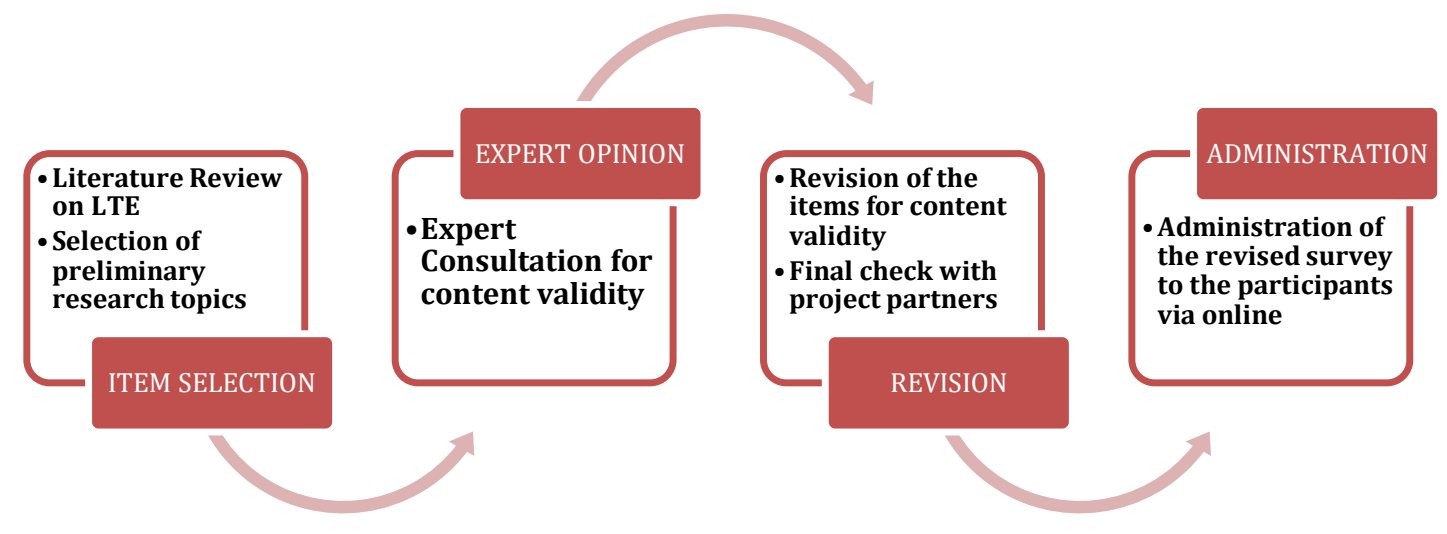

Figure 1. The developmental stages of the needs analysis survey

Figure 1 displays that firstly the items for the survey were based on the literature review on LTE in order to gain an in-depth understanding of the topics and write the preliminary items. For literature review, internationally published books on LTE (such as Hall (2016) and Gitsaki \& Alexiou (2015)) and recent issues of indexed journals on teacher education and LTE (such as Journal of Language and Education, Journal of Teachers and Teaching, European Journal of Teacher Education, Journal of Teacher Education, and TESOL Quarterly) were scanned. Moreover, at a transnational meeting of the project, twelve TEs from Turkey, Portugal and Poland focused on the discussion of the research topics gathered through literature review and shared their experiences and ideas on the items emerged. After the selection of the preliminary items from the item pool, five experts ( 2 from the field of assessment and evaluation and 3 from the field of LTE) were consulted to evaluate the preliminary items. The survey was also revised for face and content validity according to the discussions held at a transnational meeting. Finally, the survey was administered to the novice/expert researchers, teacher trainers, and academics in the field of LTE from three countries (Poland, Portugal, and Turkey) through an online survey platform. 


\section{Interviews}

In order to expand the data and elaborate on the research aim of the study, semi-structured interviews were held. Among the respondents of the needs analysis survey, 3 TEs or researchers from each context (Poland, Portugal, and Turkey) were asked to discuss on the findings of the needs analysis survey (the higher and lower needed research topics, the possible reasons, their own ideas on these findings). Furthermore, participants were asked to share their experiences on topics of and the selection process of the studies in MA, Ph.D., thesis dissertations, and/or research articles) conducted in their contexts. The interview questions are given in the appendix. The participants were chosen on a voluntary basis. Due to geographical distances between contexts, the interviews were conducted through online format. The questions were sent to the participants by email and the participants were asked to reply back in written format. Meanwhile, the participants were also informed that they could contact with the researchers for possible lack of understanding.

\section{Data Analysis}

The quantitative data of the study were collected through a needs analysis survey, which is a 5-Likert scale. A total of 23 items included in the survey were related to identifying the areas that the researchers think require more research in LTE. Reliability coefficients (Cronbach Alpha) of the scale were .85, which indicated good reliability. The participants were asked to grade according to the degrees of the necessity for further research. Descriptive statistics (e.g., frequency analysis, mean, standard deviation) and cluster analysis were applied to identify which research areas were found necessary. In light of the results of the descriptive statistics, three experts in the field categorized the findings for a better presentation of the data. The categories were named as very high, high and moderate level according to the cut-off points decided by the experts.

For the qualitative analysis of nine interviews, content analysis, a type of qualitative analysis including coding for themes, searching patterns, and making interpretations to draw conclusions (Ellis \& Barkhuizen, 2005), was used to gather the common themes. For the reliability issue, two coders read each interview of the same TE and compared their themes in order to discuss disagreements and develop a shared 
coding scheme. They worked together throughout the coding. The findings of the qualitative data were supported with significant quotations and analysed to enhance the quantitative results.

\section{Results and Discussion}

According to cluster analysis and mean scores (above 3.00), all research topics in the survey were found necessary to conduct further research in LTE. In other words, all items were specified necessary by the academics to explore more for the field of LTE. However, to investigate the research aims more in-depth, three experts analysed the findings and classified the items according to the mean scores and sum values into three main categories: very high level (4 items above mean value of 4.20), high level (15 items between mean values of 3.5-4.20), and moderate level ( 4 items below mean value of 3.5 ).

The results are supported by the extracts from the interviews to provide more insights. As given in the appendix, the interviews were held around the discussion of the items that were found very high and moderate level of research need. Due to the number of research items $(n=23)$ in the survey, the qualitative data and the extracts to support the findings were limited to the most and the least needed areas. Moreover, the discussion of the findings were meant to focus on the overall picture of the findings and particular research items since each and every research item in the survey $(n=23)$ is a wide research area, and thus it is not possible to discuss all of the research topics in the current study, which is not the scope of the study as well. Since the main aim of the study is to investigate to investigate the needs of academics and researchers in the field of LTE in a variety of contexts (Turkey, Portugal, and Poland), the findings of the needs analysis survey were presented and discussed below through three main categories of level of needs.

Table 1 below displays the research fields which received the highest interest by the participants. Professional development, practicum, classroom interaction, and teacher competencies and standardization were found considerably more necessary to be studied upon. 
Table 1. The results of the frequency analysis of the research fields of "very high level" of need

\begin{tabular}{lcccc}
\hline \multicolumn{1}{c}{ Research areas for further studies } & Mean & St. Deviation & SUM (\%) & Level of need \\
\hline $\begin{array}{l}\text { 1. Continuing professional development } \\
\text { for language teachers }\end{array}$ & 4.34 &, 709 & 60,4 & Very high \\
\hline $\begin{array}{l}\text { 2. Practicum in LTE } \\
\text { 3. Classroom Interaction and LTE }\end{array}$ & 4.32 &, 704 & 60,1 & Very high \\
\hline $\begin{array}{l}\text { 4. Teacher competencies and } \\
\text { standardization }\end{array}$ & 4,25 &, 771 & 59,1 & Very high \\
\hline
\end{tabular}

Furthermore, in interviews, the academics stated the possible reasons for this finding by highlighting more practice-oriented aspects of these topics. The researchers discussed that $C P D$, practicum, classroom interaction and teacher competencies were mostly related to the practical dimension of LTE. Therefore, it can be concluded from the findings that in LTE field, more research is needed towards the path of teaching practice for improving LTE field, which might also shed further light on the theoretical aspects of LTE. Also, the interviewees shared similar opinions while interpreting this finding. In order to expand this discussion, the following excerpts from a researcher from Portugal and one from Poland illustrate this finding:

In fact, the topics that received the highest interest in the needs analysis survey seem to prove my belief, given that they are largely concerned with teachers' real-life endeavours and tasks. R6 Portugal

All of these topics have a more practical dimension than the ones less popular in this needs analysis. It means that researching these topics may contribute to obtaining practical implications both for the researchers who have to didactic classes with students as well as their students with whom they can share their newly researched knowledge. R3 Poland

The results in Table 1 yield that $C P D$ has the highest interest among the researchers, which also supports the recent research trends of literature in the field. CPD covers several aspects of improving teacher competencies, as stated below, with an extract.

Professional development is very often emphasised on the methodology of foreign language teaching courses. Due to various processes, such as language attrition, teacher burnout, it seems to be very important to help in-service teachers improve their competencies. R1 Poland

Moreover, practicum is a topic that interests several researchers. Researchers below discuss that practicum has a significant role in LTE in order to cultivate STs for 
their future classrooms. In this line, Öztürk and Aydın (2019) list the lack of feedback and practice in LTE programs as one of the common problems confronted in preservice teacher education.

Practicum contributes to success or failure in foreign language teaching, and practicum experience may influence, to a great extent, pre-service teachers' perception of the profession.

\section{R1 Poland}

Practicum plays a leading role in LTE research. It is a wide area where many teaching components can be investigated. Student teachers can be observed in terms of teacher motivation, agency, identity, practical knowledge, use of reflective practice, use of lesson plan, giving instructions; the behaviors of mentor teachers can be investigated in terms of observation and feedback. R9 Turkey

Another result is that the research on classroom interaction is also highly needed. In this sense, Sert (2019) also highlights that classroom interaction studies are to be conducted more to increase awareness of the relationships between interaction and learning, to provide teachers with tools to utilize classroom interaction into teacher education, and to follow the change in teaching practices in time.

The last highly needed area is teacher competencies and standardization. The researcher from Turkey stresses the significance of this topic in detail.

I think the high score given for teaching competencies and standardization might stem from the desire to make the teaching standards equal or nearly equal in many teaching contexts. My personal belief is that teaching quality is so essential that many teachers experience the feeling of learned helplessness as they need to cope with under-motivated learners in their classes, especially at vocational high schools in Turkey. I believe these teachers are caught in the wind of despair, and they believe it is too late to reverse things back as these learners lost their interest in language learning before attending vocational high schools. R9 Turkey

These findings might also be interpreted in line with a study by Demir and Koçyiğit (2018) about a systematic review of research on English LTE between 1997 and 2016 in three flagship journals. They found that teacher identity, professional development, teacher/learner variables, teaching and learning issues and teacher roles were the top five popular themes in terms of recent research trends. Thus, professional development as a research topic has been popular for the last two decades. However, the current study reveals that the academics in the field still suggest more studies are needed in professional development of language teachers. 
Furthermore, the findings of the survey also indicate that a significant amount of research topics $(n=15)$ were found "high level" of need for further research. Table 2 below presents the research areas which have significant potential to study more.

Table 2. The results of the frequency analysis of the research fields of "high level of need"

\begin{tabular}{|c|c|c|c|c|}
\hline Research areas for further studies & Mean & St. Deviation & SUM (\%) & $\begin{array}{c}\text { Level of } \\
\text { need }\end{array}$ \\
\hline 5. Curriculum and materials development in LTE & 4,19 & ,750 & 58,3 & High \\
\hline 6. Processes of LTE: reflective practice & 4,17 & ,809 & 58,1 & High \\
\hline 7. Testing and assessment in LTE & 4,12 & ,880 & 57,3 & High \\
\hline $\begin{array}{l}\text { 8. Creating a language teacher training community: } \\
\text { best practice in LTE }\end{array}$ & 4,10 & ,813 & 57,1 & High \\
\hline 9. Culture/Intercultural Competence in LTE & 4,07 & ,851 & 56,7 & High \\
\hline 10. Teaching English to young learners & 4,05 & ,930 & 56,4 & High \\
\hline 11. Teacher cognition in language teaching & 4,01 & ,908 & 55,8 & High \\
\hline $\begin{array}{l}\text { 12. Technology and LTE (e.g., ICT, Blended } \\
\text { Learning, Distance Learning) }\end{array}$ & 4,00 & ,985 & 55,6 & High \\
\hline $\begin{array}{l}\text { 13. Professional cultures/ Language teacher as the } \\
\text { Professional }\end{array}$ & 3,97 & ,908 & 55,2 & High \\
\hline $\begin{array}{l}\text { 14. The knowledge base of LTE (professional/ } \\
\text { procedural/personal knowledge) }\end{array}$ & 3,96 & ,793 & 55,1 & High \\
\hline $\begin{array}{l}\text { 15. Comparative evaluation of LTE programs and } \\
\text { policies }\end{array}$ & 3,89 & ,950 & 54,2 & High \\
\hline $\begin{array}{l}\text { 16. The individual teacher (Personality, anxiety, self- } \\
\text { efficacy, motivation, teacher efficacy, autonomy) }\end{array}$ & 3,87 & ,920 & 53,9 & High \\
\hline $\begin{array}{l}\text { 17. The impact of English as a global language on } \\
\text { teacher education policy and practices (English as an } \\
\text { International Language, English as a Lingua Franca, } \\
\text { World Englishes) }\end{array}$ & 3,77 & ,909 & 52,5 & High \\
\hline $\begin{array}{l}\text { 18. Issues in Pragmatics, Sociolinguistics, and } \\
\text { Psycholinguistics in LTE }\end{array}$ & 3,66 & ,927 & 51 & High \\
\hline $\begin{array}{l}\text { 19. Comparative evaluation of post-graduate } \\
\text { programs in LTE }\end{array}$ & 3,66 & ,967 & 50,9 & High \\
\hline
\end{tabular}

It can be concluded from Table 2 that the highly needed research areas are including a wide range of studies. These areas can be summarised as teacher-oriented educational psychology-based studies (like the individual teacher, teacher cognition), comparative studies in undergraduate and postgraduate LTE programs, creating teacher communities and professional culture, teaching English to young learners, improving skills of teachers (technology \& intercultural competence). 
Since it is not reasonable to go into details of all these research topics in this study, the results can be discussed in light of the recent studies on these topics. For example, as the review of the literature also highlights, technology integration in LTE is increasingly needed. Lightfoot (2019) elaborates this need through the triple effect of (a) developing teachers' digital literacy and technical skills; (b) providing hands-on experiences of learning using technology through a dynamic relationship with their learners, and (c) improving teachers' subject and pedagogical knowledge based on their experiences on technology use.

Moreover, reflective practices in LTE are still popular as mediums of research. However, it is argued that teacher educators are not aware of the nature of the reflection, which require the changes in attitudes to become a reflective practitioner. Farrell (2018) supports the idea that in LTE, teacher educators should be a role model for reflection by analysing their own teaching practices. In this regard, Wright (2010) acknowledges that LTE should aim to produce reflective teachers through a process integrating socio-cognitive demands to introspect and collaborate with others. Recent publications of TESOL mostly focus on reflective practices in LTE, particularly in the practicum contexts (Farrell, 2018).

The last findings of the study focus on the less but still needed research areas. Table 3 below display that only four research topics were found as a "moderate level" of need for further research. These topics are related to CEFR, L1 use, corpus studies, and literature.

Table 3. The results of the frequency analysis of the research fields of "moderate level of need"

\begin{tabular}{lcccc}
\hline \multicolumn{1}{c}{ Research areas for further studies } & Mean & St. Deviation & SUM (\%) & Level of need \\
\hline $\begin{array}{l}\text { 20. Common European Framework of } \\
\text { Reference for Languages (CEFR) and LTE }\end{array}$ & 3,51 & 1,031 & 48,9 & Moderate \\
\hline 21. Own-Language Use (L1 use) in LTE & 3,50 & 1,024 & 48,7 & Moderate \\
\hline 22. Use of corpus studies in LTE & 3,42 & 1,007 & 47,6 & Moderate \\
\hline 23. Using Literature in LTE & 3,23 & 1,118 & 44,9 & Moderate \\
\hline
\end{tabular}

To explain the possible reasons behind this finding, some academics assert that these topics are mostly theory-based, as stated in the following excerpts: 
It seems that the topics are considered 'theoretical', possibly being more on the 'meta' level. Besides, some topics might still be unknown to the subjects (including the CEFR or corpus linguistics), while others may be uninteresting, such as the use of literature (in light of the dominance of CLIL). R5 Poland

Several of the topics above attempt to expand the already existing scientific knowledge base, whereas teachers perhaps need research topics that tackle "real world" questions and attempt to solve problems that teachers experience first-hand in the classroom. R7 Portugal

In particular, the interviewees emphasize that corpus studies were not taught and practiced in methodology classes of LTE programmes. Teacher trainers and researchers might not be aware of the potential uses of corpora due to lack of training. Thus, when compared to other topics, corpus studies were reported as less needed area. The following extracts from each country illustrate the finding better:

To a certain extent, I was not surprised at the lower interest of the respondents regarding the use of corpus studies and literature in LTE. Based on my experience as a teacher trainer and through contacting pre- and in-service teachers, I have hardly noticed any interest in those areas. R6 Portugal

Corpus is not introduced to us at the pre-service level, nor postgraduate studies. We also did not use it very often to improve our vocabulary knowledge. So, we are not aware of its power and its relation to the language learning approaches and technology. R8 Turkey

Although CEFR is a common official document in most European contexts, the researchers were not interested much in this topic. One of the possible reasons, as stated below, can be that there are already several studies on CEFR, or the teacher may consult the document directly without any need for research.

It somehow surprised me due to the amount of research on this topic. Also, I would expect academics and teachers to be aware of the importance the CEFR plays today. R5 Portugal The CEFR may have received a lower response rate because it is a document that teachers may consult whenever necessary. R4 Portugal

It is not so surprising that CEFR has received a low interest in a survey recently conducted as a number of studies have been conducted about this subject so far, but I believe most of these studies have remained limited to the academy setting in Turkey, and we might conduct more studies about the practical implementation of CEFR at primary and secondary levels and more longitudinal studies might be needed to observe the development and outcomes clearly. R9 Turkey

Regarding L1 use, a researcher from Portugal explain below a possible reason for this moderate level interest:

The use of L1 may also have been low in teachers' responses because there may still be an idea that the L1 should not be used in the FL classroom. R5 Portugal 
All in all, the findings of the needs analysis revealed that all of the research topics were found necessary to conduct study upon. Mostly needed areas such as professional development, practicum, classroom interaction and teacher competencies were interpreted as more practical concerns for LTE. Similarly, Alptekin and Tatar (2011), by surveying nearly 130 studies for the period 2005-2009 in Turkey found that practical concerns assume priority over theoretical issues within the studies conducted on EFL learning and teaching. When compared to the other research items, the least needed areas such as corpus use, CEFR, literature and L1 use were discussed as not interesting, not necessary and relevant, requiring more expertise (e.g. corpus).

Furthermore, another aim of the study was to provide a descriptive picture of the current implementations on choosing research topics in three LTE contexts. To this end, the interviewees were asked to share their own experiences related to their own context. It can be concluded from the interviews that the researchers in Turkey, Portugal, and Poland again share similar opinions and implementations on how they decide on the research topic and which research topics are recently conducted. The findings are summarised below one by one for each context.

Topics in the MA context in Poland are mostly related to the supervisor's research interests. Other criteria to choose research topics might depend on preservice teachers' needs and interests on the condition that the topics correspond to the research field of the seminar. The studies studied in Polish context are multiculturalism in English classes, the impact of the internship abroad on students' perceptions of English, correcting language learners' errors, language teacher identity, learner autonomy, learner differences, learner styles and strategies, classroom management, teacher development, CLIL, practicum, and material development, natural language processing, lexicography, and translation.

Similar to the Polish context, the topics of studies in the Portuguese context are based on the expertise of the supervisor. One of the interviewees has mentioned that the topics of research articles are based on the researchers' individual preferences, which are related to their previous studies. Interestingly, one of the Portuguese interviewees has highlighted the significance of the observation period the STs undergo before they engage in practicum practices. Research topics are 
sometimes identified during this observation process in the Portuguese context. The research topics are mainly in the areas of curriculum and materials development, intercultural communicative competence and intercultural awareness, English as a Lingua Franca, teaching language skills, the use of technology in the language classroom, learner motivation, multiple intelligences, natural approach, and more practical issues such as learning from songs, games, and movement, using storytelling in the young learners' classroom, and using comics in the classroom.

Furthermore, in the Turkish context, research topics are chosen according to similar criteria. First, the research interest of the supervisor is of significance so that the MA student is guided effectively. Other concerns are the practicality of reaching out to participants, the feasibility of the research design, the internationality of the results, and the international value of the study. Common research areas involve technology-enhanced language learning, applied linguistics, learner motivation, individual differences, practicum teaching, teaching young learners, professional development.

In the interviews, the researchers also elaborated their discussions through further suggestions which might be important to critically evaluate the current implementations. For example, a Turkish researcher criticized that there might be some overlaps in the research topics, which led to the repetition of the problems and suggestions. However, the field of foreign language teaching needs more realistic and localized solutions developed for the relevant and urgent issues. The opinions of another Turkish researcher are in line with the former one as the researcher focused on the need for research addressing local issues. The same researcher mentions that case studies can be handled by the researchers, and context-bound practical solutions could be found since the solutions to the same problem might differ in different regions, even in the same country. The need for research for vocational English at different levels and specialized language training for learning disabilities are also mentioned by a Turkish researcher.

Similarly, one of the Portuguese researchers highlights the significance of case studies on effective teaching. The same researcher also mentions comparative studies of teaching styles should be fostered as well as multilingualism and multiculturalism 
owing to the increasing migration flows in Europe. One of the Portuguese researchers mentions that both novice and experienced researchers reconsider foreign language teaching, given the demands of the current globalized world. Hence, the Portuguese researcher argues that research topics that help to develop new sets of competencies for foreign language teachers are crucial; and thus, this will empower the language teachers to utilize innovative teaching practices.

A number of suggestions have been shared by Polish researchers. One interviewee put forward that researchers should offer practical solutions, plans, scenarios, and activities as well as presenting theoretical knowledge. Another remarkable suggestion is about the need for research about learning difficulties and disabilities. According to another Polish researcher, more research is required about the actual behavior of the teachers and students in actual classrooms where audio and video recordings are used. Among the further opinions shared by the last researcher in the Polish context, suggested research topics such as teacher performance assessment, teacher motivation, role models for becoming language teachers were found distinguished from previously mentioned opinions.

\section{Conclusion}

This study aimed at exploring the research needs in the LTE field with the viewpoints of the academics and researchers through a descriptive picture within an Erasmus Project framework. With a needs analysis survey filled by the academics in LTE from Turkey, Portugal, and Poland, a list of research topics was compiled, including a wide array of topics. The quantitative analysis of the survey revealed that all research topics worth investigation. In particular, CPD, classroom interaction, practicum, teacher competencies, and standardization were found as highly needed research topics. On the other hand, topics such as corpus and literature studies, CEFR, and L1 use were found comparatively less needed areas. The interviews conducted with the academics from three countries also shed light on more contextual tendencies on the research topics, their current implementations, and further research suggestions. 
In sum, the current study reveals that researchers share similar concerns on choosing research topics for further study although they are from different LTE contexts. Also, some particular research topics were attributed a kind of more level of need, which may guide future researchers in the field. In this regard, it is important to note also that most of the studies focus on attitudes, perceptions and beliefs in LTE and more localness (Kleinsasser, 2013). Thus, future studies should go beyond selfreported data through more data-led, observation-based, and longitudinal studies. Also, as Kleinsasser (2013) suggests that, with regard to future directions of the research in the field, future researchers need to go beyond borders and boundaries by including citations and practices from around the world.

The study is significant in the sense that it was conducted in three different LTE contexts in different countries. Moreover, as the literature review suggests, there was no previous study conducted to find out the research needs that are driven out of the viewpoints of the academics in the field. It is hoped that novice or experienced researchers, MA, and Ph.D. students, teacher educators in LTE, gain valuable insights into the ways in which research topics to focus on more.

Although there are several implications stated above, the study has some limitations. The implementation of the survey was limited to the partner universities within the Project. Thus the survey can be conducted to other LTE contexts in different countries. The study is limited to two data collection instruments, a survey, and interviews. Therefore, further studies can be conducted with other instruments (document analysis, field notes, journals).

\section{Acknowledgement:}

This article is produced as a part of the Erasmus + project titled ILTERG "International LTE Research Group" (no: KA203-035295) funded by the Turkish National Agency. 


\section{Notes on the contributors}

Burçak Yılmaz Yakışık (Ph.D.) is a lecturer in School of Foreign Languages at Gazi University, Ankara, Turkey. Her research interests are teacher education, professional teacher agency, individual differences in learning, social interaction in language classes.

Asuman Aşık is an associate professor in the Department of English Language Teaching at Gazi University, Ankara, Turkey. She is a teacher trainer and a researcher. Her main research areas are language teacher education, technology integration and corpus use in language teaching, and young learners.

\section{References}

Akbari, R. (2007). Reflections on reflection: A critical appraisal of reflective practices in L2 teacher education. System, 35(2), 192-207.

Alptekin, C., \& Tatar, S. (2011). Research on foreign language teaching and learning in Turkey (2005-2009). Language Teaching, 44(3), 328-353.

Baecher, L., Kung, S.C., Jewkes, A. M., \& Rosalia, C. (2013). The role of video for self-evaluation in early field experiences. Teaching and Teacher Education, 36, 189-197.

Bal-Gezegin, B., \& Seferoglu, G. (2019). Continuing professional development for language teachers. In G. Y. Ekşi, L. Guerra, D. Werbińska, Y. Bayyurt (Eds.). Research trends in English language teacher education and English language teaching (pp.59-75). Evora, Portugal: University of Evora.

Bartlett, L. (1990). Teacher development through reflective teaching. In J. C. Richards \& D. Nunan (Eds.) Second language teacher education (pp. 202-214). New York: Cambridge University Press.

Benson, P. (2007). Autonomy in language teaching and learning. State of the art article. Language Teaching, 40(1), 21-40.

Chien, C. W. (2013). Analysis of language teachers' journal of classroom practice as a reflective practice. Reflective Practice, 14(1), 131-143.

Crandall, J-A. (2000). Language teacher education. Annual Review of Applied Linguistics, 20, 34-55.

Creswell, J. W. (2007). Qualitative inquiry and research design: Choosing among five approaches (2nd ed.). Sage Publications.

De Costa, P. I., \& Norton, B. (2017). Introduction: Identity, transdisciplinarity and the good language teacher. The Modern Language Teacher, 101(S), 3-14.

Demir, Y., \& Kocyigit, M. (2018). A systematic review of research on English Language Teacher Education published in three flagship journals (19972016). Online Submission, 4(1), 128-138.

El-Dib, M. A. B. (2007). Levels of reflection in action research: An overview and an assessment tool. Teaching and Teacher Education, 23(1), 24-35. 
Ellis, R., \& Barkhuizen, G. (2005). Analysing learner language. Oxford, UK: Oxford University Press.

Eröz-Tuğa, B. (2013). Reflective feedback sessions using video recordings. ELT Journal, 67(2), 175-183.

Farrell, T. S. C. (2018). Research on reflective practice in TESOL. New York, NY: Routledge.

Freeman, D. \& Johnson, K. E. (1998). Reconceptualizing the knowledge-base of language teacher education. TESOL Quarterly, 32(3), 397-417.

Gitsaki, C., \& Alexiou, T. (2015). (Eds.). Current issues in second/foreign language teaching and teacher development: research and practice. Newcastle upon Tyne, UK: Cambridge Scholars Publishing.

Gray, C. (2004). Exploring the language teacher's mind - helping student teachers see below the surface. The Language Learning Journal, 29, 23-31.

Hall, G. (2016). (Ed.) The Routledge Handbook of English Language Teaching. London, UK: Routledge.

Huang (2005). Teacher autonomy in language learning A review of the research. In K. R. Katyal, H. C. Lam \& X. J. Ding (Eds.), Research Studies in Education (pp. 203-218). Faculty of Education, the University of Hong Kong.

Husu, J., Toom, A., \& Patrikainen, S. (2008). Guided reflection as a means to demonstrate and develop student teachers' reflective competencies. Reflective Practice: International and Multidisciplinary Perspectives, 9(1), 37-51.

Johns, A. M., \& Dudley-Evans, T. (1991). English for specific purposes: International in scope, specific in purpose. TESOL Quarterly, 25, 297-314.

Johnson, K. E. (2013). Innovation through teacher education programs. In K. Hyland \& L. Wong (Eds.), Innovation and change in English language education (pp. 75-89). New York, NY: Routledge.

Jones, J. F. (2004). The many benefits of a research component in English language teacher education: A case study. Prospect, 19(2), 25-38.

Kabilan, M., Adlina, W., \& Embi, M. (2011). Online collaboration of English language faculty for meaningful professional development experiences. English Teaching: Practice and Critique, 10(4), 94-115.

Kleinsasser, R. C. (2013). Language teachers: Research and studies in language(s) education, teaching, and learning in Teaching and Teacher Education, 19852012. Teaching and Teacher Education, 29, 86-96.

Lee, I. (2007). Preparing pre-service English teachers for reflective practice. ELT Journal, 61, 321-329.

Lightfoot, A. (2019). ICT and English Language Teacher Education. In S. Walsh \& S. Mann, (Eds.) The Routledge Handbook of English Language Teacher Education, (pp. 52-67). London, UK: Routledge.

Lin, Z. (2015). In-service professional development in an online environment: What are South Australian English as an additional language or dialect teachers' views?. Professional Development in Education, 41(3), 527-545.

Ling, I. (2007). Fostering teacher autonomy in the use of English teaching materials. CELEA Journal, 30(1), 96-102.

Luk, J. (2008). Assessing teaching practice reflections: Distinguishing discourse features of 'high' and 'low' grade reports. System, 36(4), 624-641.

Mann, S. M., \& Tang, E. H. H. (2012). The role of mentoring in supporting novice English language teachers in Hong Kong. TESOL Quarterly, 46(3), 472-495. 
Matei, G. S. (2002). Student teachers as researchers: An inquiry-oriented approach to initial teacher education. Ph.D. dissertation, University of Exeter, UK.

Meng, J. \& Tajaroensuk, S. (2013). An investigation of tertiary EFL teachers' problems in their in-service professional development. Journal of Language Teaching and Research, 4(6), 1356-1364.

Nunan, D. (1988). Syllabus design. Oxford, UK: Oxford University Press.

Öztürk, G., \& Aydın, B. (2019). English Language Teacher Education in Turkey: Why do we fail and what policy reforms are needed?. Anadolu Journal of Educational Sciences International, 9(1), 181-213.

Patton, M. Q. (2015). Qualitative research \& evaluation methods: Integrating theory and practice. Washington DC, USA: Sage publications.

Pyhältö, K., Pietarinen, J., \& Soini, T. (2015). Teachers' professional agency and learning - from adaption to active modification in teacher community. Teachers and Teaching: Theory and Practice, 21(7), 811-830.

Rashid, A. R. (2018). Dialogic reflection for professional development through conversations on social networking site, Reflective Practice, 19(1), 105-117.

Richards, J. C., \& Crookes, G. (1988). The practicum in TESOL. TESOL Quarterly, $22,9-27$.

Richards, J. C. (1990). The language teaching matrix. Cambridge: Cambridge University Press.

Richards, J. C., Platt, J., \& H. Platt. (1992). Longman Dictionary of Language Teaching and Applied Linguistics. London, UK: Longman

Richards, J. C. (2004). Towards reflective teaching. The Language Teacher, 33, 2-5.

Richards, J. C., \& Farrell, T. S. C. (2005). Professional development for language teachers. New York, USA: Cambridge University Press.

Schon, D. A. (1983). The reflective practitioner: How professional think in action. New York, USA: Basic Books.

Schon, D. A. (1987). Educating the reflective practitioner. San Francisco, USA: Jossey Bass.

Sert, O. (2019). Classroom Interaction and language teacher education. In S. Walsh \& S. Mann, (Eds.) The Routledge Handbook of English Language Teacher Education, (pp. 216-238). London, UK: Routledge.

Stoynoff, S. (1999). The TESOL practicum: An integrated model in the US. TESOL Quarterly, 33(1),145-151.

Susoy, Z. (2015). Watch your teaching: A reflection strategy for EFL pre-service teachers through video recordings, Procedia-Social and Behavioral Sciences, 199, 163-171.

Tschannen-Moran, M., \& Hoy, A. W. (2001). Teacher efficacy: Capturing an elusive construct. Teaching and teacher education, 17(7), 783-805.

Wallace, M. J. (1991). Training foreign language teachers: A reflective approach. Cambridge, UK: Cambridge University Press.

Walsh, S. \& Mann, S. (Eds). (2020). The Routledge Handbook of English Language Teacher Education. London, UK: Routledge.

Wichadee, S. (2012). Factors related to professional development of English university teachers in Thailand. Journal of Education for Teaching, 38(5), 615-627.

Wright, T. (2010). Second language teacher education: Review of recent research on practice. Language teaching, 40(3), 259-296. 
Wyatt, M. (2014). Towards a re-conceptualization of teachers' self-efficacy beliefs: Tackling enduring problems with the quantitative research and moving on. International Journal of Research \& Method in Education, 37(2), 166-189.

Yakışık, B. Y., Fişne, F. N., \& Ekşi, G. Y. (2019). Sense of professional agency in ELT practicum. Comparison of Polish, Portuguese and Turkish contexts. Journal of Language and Linguistic Studies, 15(4), 1317-1331.

Yang, S. H. (2009). Using blogs to enhance critical reflection and community of practice. International Forum of Educational Technology \& Society, 12(2), 11-21.

Yesilbursa, A. (2011). Reflection at the interface of theory and practice: An analysis of pre-service English language teachers' written reflections. Australian Journal of Teacher Education, 36(3), 49-62.

Appendix: Semi-guided interview questions for "Needs Analysis for Research in Language Teacher Education"

Question 1: The findings of the needs analysis indicate that the following research topics received the lowest interest (CEFR, L1 use, corpus studies and using literature in LTE). What do you think about the reasons behind this finding? What do you think about these research areas in language teacher education?

Question 2. The findings of the needs analysis indicate that the following research topics received the highest interest (CPD, Practicum, Classroom Interaction, teacher competencies and standardization). What do you think about the reasons behind this finding? What do you think about these research areas in language teacher education?

Question 3. What are the topics of the studies (such as the studies in master, $\mathrm{PhD}$, thesis dissertations and/or research articles) conducted in your context (at your department, at graduate programs)? How are these research topics chosen?

Please share your further opinions and suggestions about the areas in LTE that require more research to guide novice and experienced researchers in the field. 